\title{
СЕКЦИОННЫЕ ДОКЛАДЫ
}

\section{СЕКЦИЯ 1. ПРОБЛЕМЫ И ОПЫТ ПРЕПОДАВАНИЯ ФИЗИКИ, АСТРОНОМИИ И ДИСЦИПЛИН ФИЗИКО- ТЕХНИЧЕСКОЙ НАПРАВЛЕННОСТИ}

\author{
УДК 531, 372.853
}

DOI: $10.33184 / \mathrm{mppe}-2021-11-10.8$

\author{
О СТO \\ Абдуллин А.У.
}

Башкирский государственный университет, г. Уфа, Россия

В своем докладе мы продолжаем обзор трудных, на наш взгляд, мест вузовской механики из курса общей физики $[1,2]$.

В изложении специальной теории относительности (СТО) в основных курсах механики прослеживается противоречивый подход. Возьмем, к примеру, троицу классических учебников по механике - С.П.Стрелкова, А.Н.Матвеева и Д.В.Сивухина. В соответствующем томе курса А.Н.Матвеева указанная тема фигурирует даже в названии: «Механика и теория относительности», что красноречиво говорит о важности темы для автора и объеме изложения. В учебнике С.П.Стрелкова название стандартное, но в оглавлении - значительная глава в полста страниц. А вот у Д.В.Сивухина цельного раздела по СТО нет, но есть ссылка во введении: «... уже в первом томе дается некоторое представление об идеях теории относительности. ... Однако систематическое изложение вопросов релятивистской и квантовой механик будет дано в других томах курса после изложения электрических и оптических явлений.»

Из этого следует вывод о первой сложности изучения СТО в курсе механики: недостаточность знаний слушателей для систематичного изложения в первую очередь в области электродинамики, а также оптики. Поэтому возможно только фрагментарное изложение основ СТО, что имеет свои плюсы в условиях хронического дефицита учебных часов. Основное внимание уделяется преобразованиям Лоренца и физическим следствиям из них. Также определяются инварианты указанных преобразований и вводятся четырехвекторы. Кроме того, в других разделах курса необходимо постоянно напоминать о зависимости массы от скорости, что позволяет определить границы применимости классической нерелятивистской механики.

Другой сложностью является невозможность полноценного применения эксперимента для иллюстрации и подтверждения теоретических выводов. Причем как лекционного эксперимента, так и ссылок на результаты «большой» экспериментальной науки. 
Как бы Вы ни оформляли постановку эксперимента при доказательстве следствий преобразований Лоренца - при помощи мела, тряпки и доски или в сложных красочных презентациях - это всего лишь «гипотетические» опыты, ничего общего не имеющие с полноценным лекционным экспериментом. А причиной является, разумеется, масштаб скоростей.

Что касается экспериментального подтверждения СТО, то тут проблема в другом. Справедливость механики Энштейна подтверждена многими замечательными опытами, но практически все они проведены в рамках атомной и ядерной физики. А это опять-таки, накладывает ограничения на применение их результатов в курсе механики на 1-м курсе из-за недостаточных знаний слушателей по этим разделам [3]!

\section{Литература}

1. Абдуллин А.У. Тензор инерции «первашам». // Тезисы докладов ХІ Международной школы-конференции для студентов, аспирантов и молодых ученых «Фундаментальная математика и ее приложения в естествознании», г.Уфа, 2020 г. С.221-222.

2. Абдуллин А.У. Как разобраться с моментами. // Сборник материалов V Всероссийской научно-методической конференции «Проблемы современного физического образования». г.Уфа, 2019 г. С.202-204.

3. Абдуллин А.У., Акманова Г.Р. Реализация модульно-рейтинговой системы обучения при изучении механики и оптики в курсе общей физики в классическом университете // В сборнике: Проблемы современного физического образования. Сборник материалов III Всероссийской научнометодической конференции. 2015. С. 169-171.

() Абдуллин А.У., 2021 г. 